\title{
The influence of the inverter switching frequency on rotor losses in high-speed permanent magnet machines : an experimental study
}

\section{Citation for published version (APA):}

Merdzan, M., Paulides, J. J. H., Borisavljevic, A., \& Lomonova, E. A. (2016). The influence of the inverter switching frequency on rotor losses in high-speed permanent magnet machines : an experimental study. In Proceedings - 2015 IEEE International Electric Machines and Drives Conference, IEMDC 2015 (pp. 1628-1633). [7409281] Institute of Electrical and Electronics Engineers. https://doi.org/10.1109/IEMDC.2015.7409281

DOI:

10.1109/IEMDC.2015.7409281

Document status and date:

Published: 16/02/2016

\section{Document Version:}

Accepted manuscript including changes made at the peer-review stage

\section{Please check the document version of this publication:}

- A submitted manuscript is the version of the article upon submission and before peer-review. There can be important differences between the submitted version and the official published version of record. People interested in the research are advised to contact the author for the final version of the publication, or visit the DOI to the publisher's website.

- The final author version and the galley proof are versions of the publication after peer review.

- The final published version features the final layout of the paper including the volume, issue and page numbers.

Link to publication

\footnotetext{
General rights

- You may freely distribute the URL identifying the publication in the public portal. follow below link for the End User Agreement:

www.tue.nl/taverne

\section{Take down policy}

If you believe that this document breaches copyright please contact us at:

openaccess@tue.nl

providing details and we will investigate your claim.
}

Copyright and moral rights for the publications made accessible in the public portal are retained by the authors and/or other copyright owners and it is a condition of accessing publications that users recognise and abide by the legal requirements associated with these rights.

- Users may download and print one copy of any publication from the public portal for the purpose of private study or research.

- You may not further distribute the material or use it for any profit-making activity or commercial gain

If the publication is distributed under the terms of Article $25 \mathrm{fa}$ of the Dutch Copyright Act, indicated by the "Taverne" license above, please 


\title{
The influence of the inverter switching frequency on rotor losses in high-speed permanent magnet machines: an experimental study
}

\author{
M. Merdzan, J. J. H. Paulides, A. Borisavljevic, and E. A. Lomonova
}

\begin{abstract}
Harmonic content of the output voltage of pulse width modulated voltage source inverters (PWM VSI) is determined by the switching frequency. On the other hand, rotor losses in high-speed permanent magnet (PM) machines are caused, among other factors, by harmonics in stator currents. These harmonics are determined by the harmonics in the inverter output voltage, and therefore dependent on the switching frequency. In high-speed PM machines, due to the high fundamental frequency, harmonics in the stator currents caused by PWM are located at very high frequencies. Measurement of rotor losses caused by these harmonics in a structure with a conductive retaining sleeve on the rotor which is prone to eddy currents might be very challenging. This paper investigates issues related to this measurement and presents a measurement method which results are compared with results from a $2 \mathrm{D}$ analytical model that takes into account eddy currents in the rotor.
\end{abstract}

Index Terms-AC machines, eddy currents, electromagnetic measurements, harmonic analysis, loss measurement, motor drives, permanent magnet machines, pulse width modulation inverters, rotating machines, rotors, switching frequency

\section{INTRODUCTION}

Rotor eddy current losses in high-speed permanent magnet (PM) machines can significantly influence the overall machine performance due to sensitivity of rare earth magnets to temperature increase [1]. Although they are usually not so influential form the efficiency point of view, their role is significant because they cause heat generation inside the magnet or very close to it, in the retaining sleeve. Main causes of rotor losses are the permeance variation due to stator slotting, non-sinusoidal waveform of stator currents [2] and non-sinusoidal spatial distribution of armature conductors [3], [4]. The waveform of the stator currents is influenced by the switching of the power electronics converter that supplies the machine.

Switching losses in pulse width modulated voltage source inverters (PWM VSI) are proportional to the switching frequency and they decrease the overall drive efficiency. A

The authors would like to thank Micro Turbine Technology BV for cooperation on the development of a high speed generator for micro-CHP, as well as KIC InnoEnergy for providing research and development funds.

M. Merdzan, J. J. H. Paulides and E. A. Lomonova are with the Department of Electrical Engineering, Eindhoven University of Technology, $5600 \mathrm{MB}$ Eindhoven, The Netherlands (e-mail: m.merdzan@tue.nl).

A. Borisavljevic is with Micro Turbine Technology BV, De Rondom 1, 5612 AP, Eindhoven (e-mail: aleksandar@mtt-eu.com). reduction of the switching frequency usually improves efficiency of the drive provided, however, that it does not bring about a significant deterioration of stator currents and the corresponding increase of frequency-dependent losses inside the machine. Such losses can, in turn, cause partial or full demagnetization of the rotor magnet and a machine damage or failure. Therefore, the correlation between rotor losses and the switching frequency becomes very important for a design of high-speed electrical drives. Theoretical analysis of this kind was reported in [2] and applied to different armature winding configurations in [4]. The aim of this paper is to investigate possibilities for measurement of PWM caused rotor losses in high speed PM machines and compare the findings with theoretical predictions.

\section{ROTOR LOSSES IN INVERTER-FED PM MACHINES - MODELING AND MEASUREMENT}

A very useful tool for the calculation of magnetic field in permanent magnet (PM) machines is the harmonic modeling (HM) method [5]. To apply this method, the armature reaction field, main cause of rotor losses in PM machines, needs to be expressed in terms of the armature current. In [2], by combining the harmonic modeling method with analytical expressions for the output voltage of PWM voltage source inverter obtained from [6] a 2D analytical model for rotor losses in inverter-fed PM machines was introduced. By using double Fourier series representation of the PWM inverter output voltage, armature reaction field is represented as a summation over both time harmonics in the armature currents and spatial harmonics in the armature winding distribution. Although the inverter output voltage is the original source of the armature field in PM machines, use of HM imposes armature currents to be used as a field source. Therefore, the impedance of the armature circuit needs to be known [2]. The proposed analytical method was successfully verified by $2 \mathrm{D}$ transient finite element analysis, which is, for the considered high-frequency harmonics, very time consuming. In this study, the finite element analysis is not employed, since the same machine is used as in [2].

By using the armature reaction field solution in the rotor reference frame, rotor eddy-current losses can be calculated 
by applying Pointing's theorem:

$$
P_{\text {rotor }}=\frac{1}{2} \sum_{\text {time space }} \sum_{S} \operatorname{Re} \oint_{S}\left(\hat{E}_{z}\left(r, \varphi_{r}\right) \hat{H}_{\varphi}^{*}\left(r, \varphi_{r}\right)\right) d S
$$

where terms in the brackets represent the complex amplitude of the induced electric field (which has only the axial component) and the complex conjugated amplitude of the azimuthal component of the magnetic field strength vector, both dependent on radial $(r)$ and azimuthal $\left(\varphi_{r}\right)$ coordinate. The integration is done over the surface surrounding the rotor.

Measurement of rotor losses in PM machines is usually done indirectly, because they appear together with losses in other machine parts. One approach for estimation of rotor losses is the thermometric method, which requires accurate measurement of the rate of change of rotor temperature [7]. This method is difficult to implement with high-speed machines, since the appropriate physical connection of thermal sensors is difficult to realize.

Alternatively, rotor losses can be obtained by measuring input and output power in a machine and then extracted by segregation from other loss components. To apply the loss segregation method, all loss components that were present in the given experiment need to be known, like in [8]. If values of some loss components are estimated with insufficient accuracy, this method cannot give satisfactory results. An additional problem that accompanies this method is a possibility of getting a high relative error of the measurement if the loss component of interest is small in comparison to the input and output power and other loss components [9]. This is usually the case with rotor losses occurring in high-speed PM machines.

In the machine analyzed in this paper, bearing losses are highly dependent on temperature of the lubrication oil. This temperature is not regulated precisely and it is very difficult to get stabile conditions for the measurement. Since the bearing losses take the highest portion of the overall losses (more than one order of magnitude higher that the expected rotor losses) any measurement of rotor losses including the rotor rotation would result in high measurement uncertainty.

To avoid previously mentioned issues related to the experimental determination of rotor losses, the loss segregation in this paper is done by performing measurements in two different tests: locked rotor and no rotor test (in which the rotor is removed and only stator losses are present). In this way, only three different loss components appear in the measurement: stator iron losses, copper losses and rotor eddy current losses.

\section{MEASUREMENT APPROACH AND CONDITIONS REQUIRED FOR THE SEGREGATION OF LOSSES}

If the total input power of a PM machine in a locked rotor test is $P_{l r}$, and the total input power in a test where the rotor is removed is $P_{n r}$, these two power terms can be written as:

$$
\begin{aligned}
P_{l r} & =P_{C u}+P_{F e}+P_{\text {rotor }} \\
P_{n r} & =P_{C u}+P_{F e}
\end{aligned}
$$

In (2) $P_{C u}$ stands for copper losses, $P_{F e}$ for the iron losses caused by stator currents (armature field) and $P_{\text {rotor }}$ stands for rotor losses. From (2) rotor losses can be obtained by:

$$
P_{\text {rotor }}=P_{l r}-P_{n r}
$$

In order to correctly obtain rotor losses from the measured input power in two tests, it must be ensured that the remaining power terms $\left(P_{C u}\right.$ and $\left.P_{F e}\right)$ have same values in both tests. Having in mind that $\mathrm{AC}$ resistance of windings depends on both temperature and the frequency of the current Table I summarizes parameters that have to be maintained at same values in both tests in order to keep $P_{C u}$ and $P_{F e}$ unchanged.

Table I

PARAMETERS MAINTAINED CONSTANT IN LOCKED ROTOR AND NO ROTOR TEST

\begin{tabular}{cc}
\hline \hline Parameter & Symbol \\
\hline \hline Frequencies of current harmonics & $f_{I_{h}}$ \\
\hline RMS values of the current harmonics & $I_{r m s_{h}}$ \\
\hline Frequencies of flux density harmonics & $f_{B_{h}}$ \\
\hline Peak values of flux density harmonics & $B_{\max _{h}}$ \\
\hline Temperature in the stator & $T_{s}$ \\
\hline
\end{tabular}

The high-speed PM machine used for the measurement is shown in Fig. 1. It has a diametrically magnetized cylindrical magnet indicated in orange and a retaining sleeve made of Inconel, indicated in turquoise. Armature winding coils are marked with red, blue and green for different phases. Dimensions and parameters of the considered machine are shown in Table II. Since the relative magnetic permeability of the rotor is very close to 1 , the reluctance of the machine magnetic circuit in both tests is nearly the same. Therefore presence/absence of the rotor does not affect the magnetic flux density in the machine if same currents are applied in both tests. However, the influence of rotor eddy currents on the flux density in the machine in the locked rotor test could be significant, especially at high frequencies.

Table II

DIMENSIONS AND PARAMETERS OF THE CONSIDERED MACHINE

\begin{tabular}{ccc}
\hline \hline Quantity & Value & Symbol \\
\hline \hline Fundamental frequency [kHz] & 4 & $f_{0}$ \\
Pole number & 2 & $p$ \\
Stack length [mm] & 26 & $h$ \\
Magnet radius [mm] & 5.5 & $r_{m}$ \\
Sleeve outer radius [mm] & 7.5 & $r_{s l}$ \\
Stator inner radius [mm] & 9 & $r_{s i}$ \\
Stator outer radius [mm] & 27 & $r_{s o}$ \\
Magnet recoil permeability & 1.035 & $\mu_{m}$ \\
Sleeve relative permeability & 1 & $\mu_{s l}$ \\
Magnet conductivity [S/m] & $6.25 \cdot 10^{5}$ & $\sigma_{m}$ \\
Sleeve conductivity [S/m] & $8.3 \cdot 10^{5}$ & $\sigma_{s l}$ \\
\hline \hline
\end{tabular}




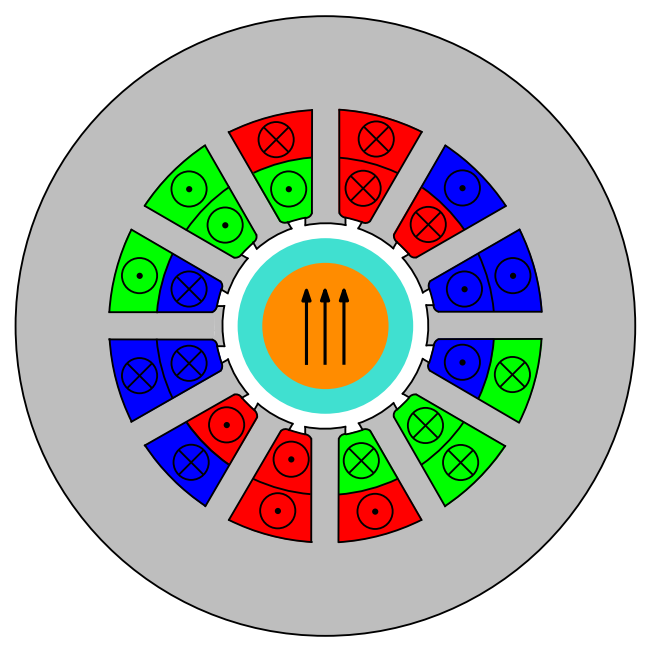

Figure 1. High-speed PM machine used for the measurement.

Models for the calculation of copper and iron losses at PWM frequencies in the considered machine which would result in satisfactory accuracy are not available to the authors. Therefore, it is difficult to assess in advance how to control armature currents or voltages in order to keep stator losses at a same value in two tests. The AC resistance that could be measured at terminals of the armature winding (in no rotor test) contains information about both copper and iron losses and the resistance corresponding to only one loss component cannot be extracted. To assess the flux linkage of the armature windings with a given supply voltage (and consequently iron losses) the leakage inductance should be known in advance as well, since it takes a portion of the applied voltage. Although there are models available for an approximate calculation of the leakage inductance [10], it is influenced by the geometry of the end windings in the specific machine and it is difficult to calculate it precisely.

Having in mind all previously mentioned limitations, the choice is made to perform the measurements by maintaining the armature currents fixed in both tests. Under normal operating conditions of the considered machine, copper losses are much higher that iron losses and it is assumed that the same relation is valid in this measurement. By maintaining the currents, copper losses are kept constant in both measurements, if the stator temperature is also kept constant. However, the reaction field of eddy currents in the rotor could result in a change of the iron losses.

\section{THE ABILITY TO MAINTAIN STATOR CURRENTS USING PWM VSI SUPPLY}

In order to assess possibilities for performing rotor loss measurement using locked rotor and no rotor tests, the considered high-speed PM machine is connected to a 3 phase PWM voltage source inverter and stator currents are measured with an oscilloscope in both tests. The stator is water cooled using the existing cooling jacket. Temperature in the stator is measured by the embedded Pt100 sensor and maintained at the same value in both tests.

The inverter is controlled to maintain same value of the fundamental component of the current. Spectra of the measured currents are shown in Fig. 2, where the fundamental frequency of the current is $4 \mathrm{kHz}$ and RMS value is $2 \mathrm{~A}$. It can be seen that corresponding harmonic components of the current have different values although corresponding voltage harmonics are same. The reason for this is different change of the phase impedance and the synchronous inductance with the frequency. The dependency of the impedance and the inductance on frequency in locked rotor and no rotor test are shown in Fig. 3, where the measurement is done by supplying a sinusoidal current with RMS value of $0,5 \mathrm{~A}$ in the whole frequency range.

The effect of inductance decrease is caused by the influence

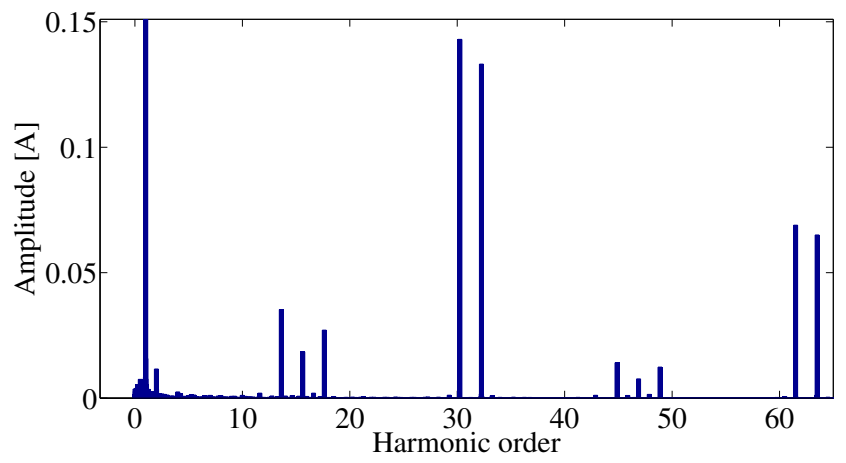

(a)

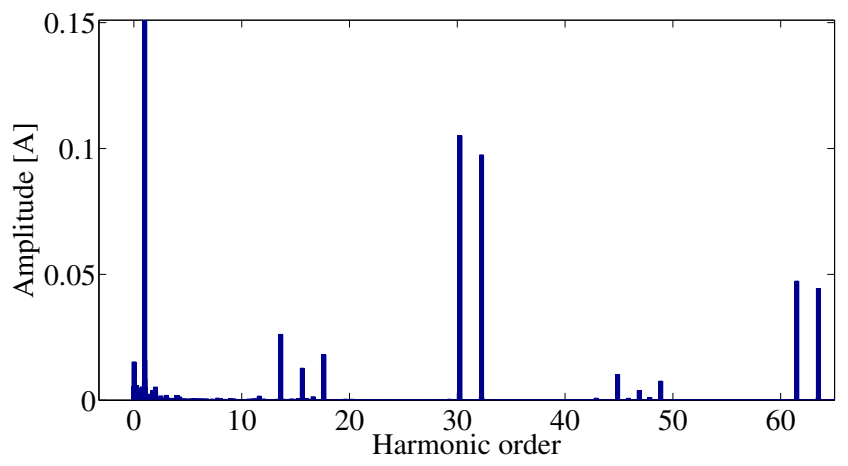

(b)

Figure 2. Current spectra obtained with PWM VSI supply: In locked rotor test (a) and in no rotor test (b).

of the reaction field of the rotor eddy currents [11]. From Fig. 3 it can be seen that for lower frequencies (below $5 \mathrm{kHz}$ ) there is no significant difference between impedance obtained in two tests. Therefore, to get the same fundamental component of the current in both tests, same fundamental component of the voltage is required. This results in the same amplitude modulation ratio, set up by the controller.

The amplitude modulation ratio determines the amplitude of the fundamental component of the voltage and at the same time amplitudes of all other voltage harmonics, which are also dependent on it [6]. However, due to different values of the 


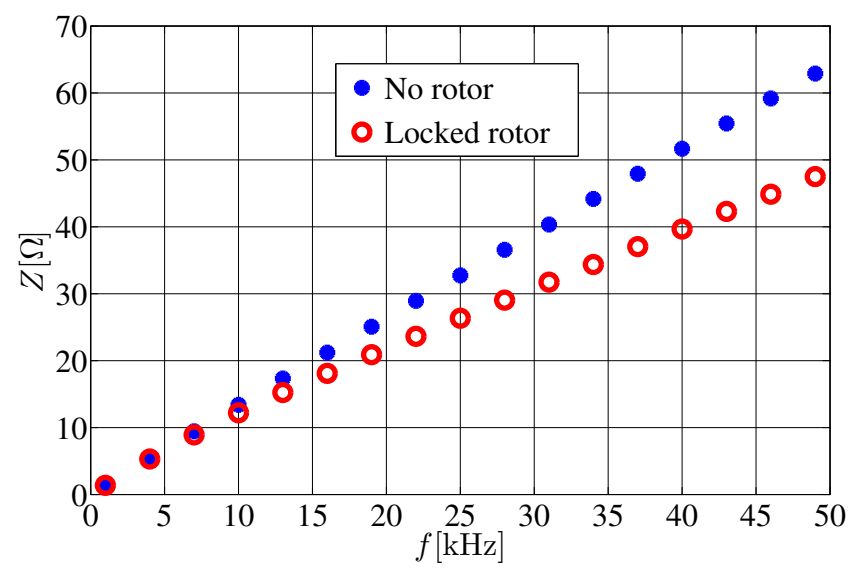

(a)

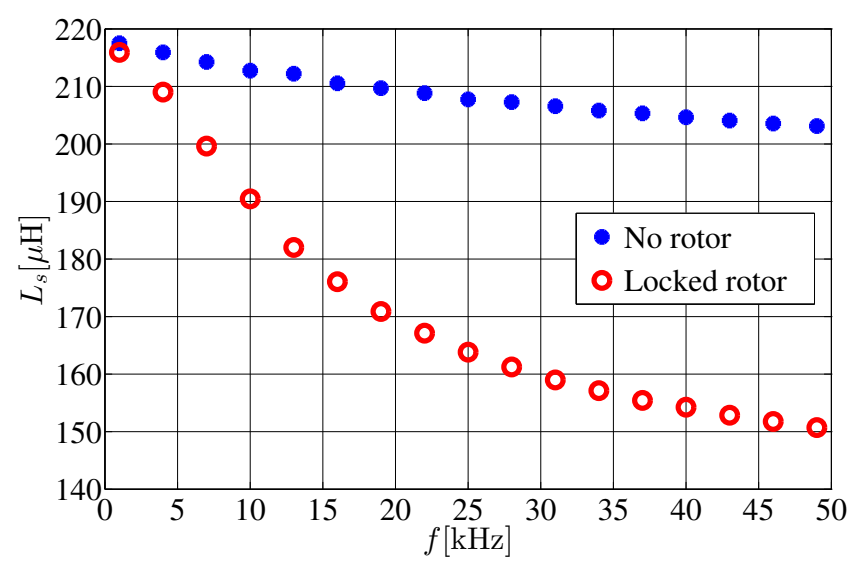

(b)

Figure 3. Change of the measured phase impedance (a) and the measured synchronous inductance (b) with frequency.

impedance seen by the armature circuit, stator currents cannot be maintained at same values in both tests and a different measurement approach needs to be used.

\section{ROTOR LOSSES MEASUREMENTS USING AC VOLTAGE SUPPLIES}

To avoid limitations imposed by the inverter, this alternative setup for the rotor losses measurement is proposed. Two single phase sinusoidal power supply units with the variable output voltage and frequency are used in these tests, as shown in Fig. 4(a), where the power supplies are indicated with $U_{1}$ and $U_{2}$. The phase shift between generated voltages is set to be 120 degrees to achieve balanced currents in all three phases.

By varying amplitudes of voltages $U_{1}$ and $U_{2}$, the stator currents are maintained at the same value in both tests and the measurement is repeated for every harmonic component of interest. Since two identical machines are available the measurement is done on both of them to get more reliable results. The windings of the two machines are connected in parallel and the measurement is done on both of them simultaneously to reduce the number of repetitions.
Input power in locked rotor test and no rotor test is measured using six channels of a digital power analyzer, where each channel is used to measure the voltage and the current of a single phase of one machine. In Fig. 4(b) a photo of the used high-speed PM machines is shown.

To verify the method, the measurement of rotor losses is

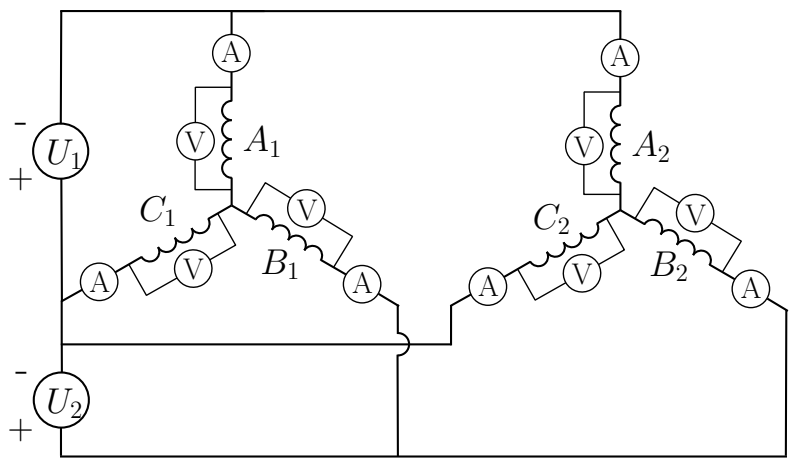

(a)

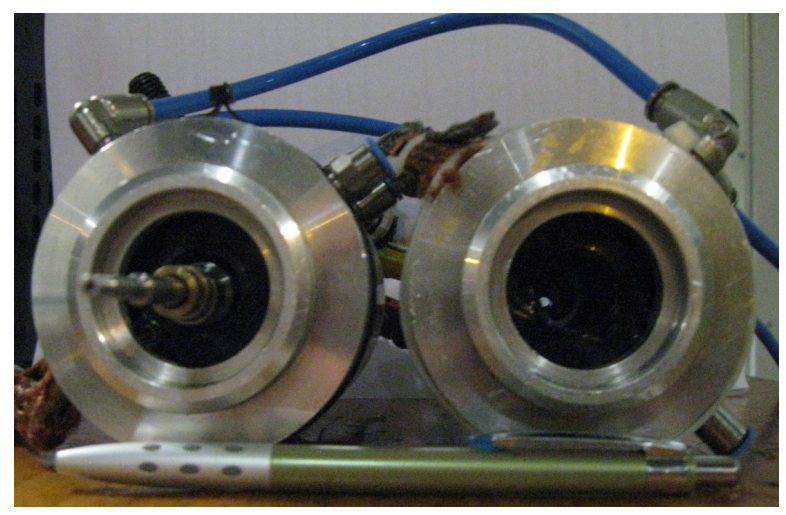

(b)

Figure 4. The connection diagram (a) and the photo of the used equipment (b).

first done by maintaining the RMS value of stator currents at $0,5 \mathrm{~A}$ at different frequencies. The measurement results are compared with results from the analytical model that was obtained by adopting the model presented in [2]. The results are shown in Fig. 5(a). A good agreement is achieved between the analytical model and the measurement. The analytical model gives a slightly lower results. The reason for this is the influence of the magnetic field generated by the end windings ( $3 \mathrm{D}$ effect), which is not included in the analytical model. It can also be seen that one of the machines (in Fig. 5(a) indicated as $M_{2}$ ) has to some extent higher losses than the other machine, which is most likely caused by small differences in the machine manufacturing.

Once the measurement method is verified, the measurement is done by setting up currents corresponding to the PWM harmonics of the VSI output voltage. From Fig. 2 it can be seen that the most dominant current harmonic components in the considered tests are those from the second sideband group. This is typical for low values of the amplitude modulation ratio 
where there is no induced EMF. Therefore, the measurement is done with these two current harmonic components for every considered value of the inverter frequency modulation ratio, which is sufficient for the model verification.

In these tests, the fundamental frequency, for which the PWM harmonics are emulated, is chosen to be $1,5 \mathrm{kHz}$. This is done to be able to generate desired values of the stator currents, since that would be very difficult to achieve with used voltage supplies at frequencies of PWM harmonics corresponding to the fundamental frequency of $4 \mathrm{kHz}$. Nevertheless, the method does not lose its generality in this way. The range in which the frequency modulation ratio $\left(m_{f}\right)$ is varied is between 9 and 16 (switching frequency between 13.5 and $24 \mathrm{kHz}$ ).

In Fig. 5(b) the measurement results are shown for previously mentioned two harmonic components from the second sideband group. Again, a good agreement between the measurement and the analytical model is achieved, which confirms the validity of the proposed analytical method. It can be seen that for lower values of the frequency modulation ratio $\left(m_{f}\right)$ the same relation between measured and calculated losses is maintained as in Fig. 5(a) - measured losses are slightly higher than calculated ones. However, with increasing $m_{f}$ measured losses become lower than the analytical model prediction and this trend is clearly visible from Fig. 5(b).

The change in this trend is again caused by the influence of the rotor eddy currents on the magnetic flux density in the machines, which starts to be significant. The flux density in the locked rotor test causes a decrease in the iron losses and therefore in overall stator losses in the locked rotor test. These become lower than the stator losses in no rotor test. Because of this effect, the measured rotor losses, obtained as $P_{l r}-P_{n r}$, are underestimated. This transition happens approximately for $m_{f}=12$, where two considered PWM harmonics are located around $36 \mathrm{kHz}$.

Again, losses measured on machine $M_{2}$ are slightly higher those measured on machine $M_{1}$ and this trend is consistent. Values of measured input powers in locked rotor test $\left(P_{l r}\right)$ and no rotor test $\left(P_{n r}\right)$ for both machines are shown in Table III.

Table III

MEASURED VALUES OF INPUT POWERS FOR BOTH MACHINES

\begin{tabular}{ccccccccc}
\hline \hline$m_{f}$ & 9 & 10 & 11 & 12 & 13 & 14 & 15 & 16 \\
\hline \hline$P_{l r}\left(M_{1}\right)$ & 8.87 & 8.06 & 7.40 & 6.81 & 6.39 & 6.05 & 5.68 & 5.33 \\
$P_{l r}\left(M_{2}\right)$ & 9.07 & 8.23 & 7.55 & 6.95 & 6.51 & 6.15 & 5.78 & 5.42 \\
$P_{n r}\left(M_{1}\right)$ & 4.14 & 3.97 & 3.88 & 3.78 & 3.70 & 3.69 & 3.62 & 3.48 \\
$P_{n r}\left(M_{2}\right)$ & 4.11 & 3.93 & 3.84 & 3.74 & 3.66 & 3.65 & 3.58 & 3.45 \\
\hline \hline
\end{tabular}

\section{CONCLUSION}

This paper presents an experimental study about rotor losses caused by PMW harmonics in high-speed permanent magnet machines. To minimize the influence of uncertainty in knowing other loss components, the measurement has been done by performing locked rotor and no rotor test with fixed stator currents. Conditions required for the segregation of losses have

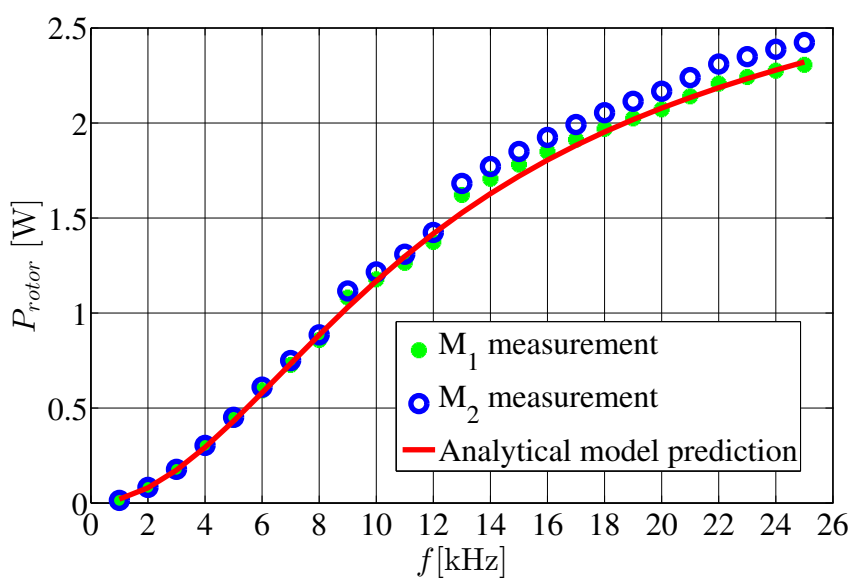

(a)

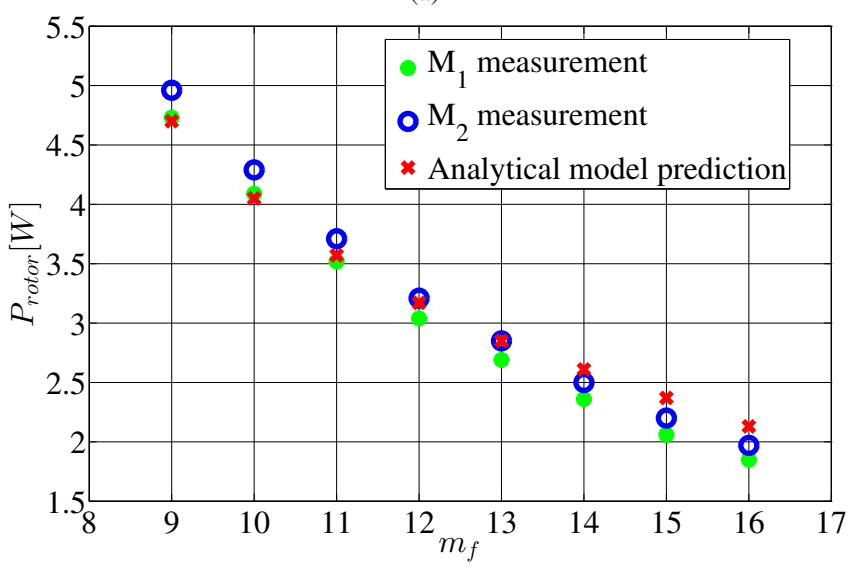

(b)

Figure 5. Results of rotor losses measurement: with RMS current of 0,5 A (a) and with varying frequency modulation ratio (b).

been analyzed and it has been shown it is not possible to perform this measurement with a standard 3 phase inverter due to a significant inductance drop at high frequencies.

An alternative measurement setup has been introduced and the measurement results have been compared with those from an analytical model. Despite a small discrepancy introduced by ignoring $3 \mathrm{D}$ effects in the analytical model, an additional disparity has been observed, which makes measured losses lower than calculated ones at high frequencies. This effect has been attributed to a drop in iron loses. A more thorough analysis of this effect, as well as looking for a way to keep stator losses constant in a wide frequency range will be a subject of the future research.

\section{REFERENCES}

[1] E. P. Furlani, Permanent Magnet and Electromechanical Devices. Academic Press, USA, 2001.

[2] M. Merdzan, A. Borisavljevic, and E. A. Lomonova, "Modeling the influence of commutation in voltage source inverters on rotor losses of permanent magnet machines," in Power Electronics and Applications (EPE'14-ECCE Europe), 2014 16th European Conference on, Aug 2014, pp. $1-10$.

[3] S. Jumayev, A. Borisavljevic, K. O. Boynov, E. A. Lomonova, and J. Pyrhonen, "Analysis of rotor eddy current losses in slotless high-speed 
permanent magnet machines," in Power Electronics and Applications (EPE'14-ECCE Europe), 2014 16th European Conference on, Aug 2014, pp. $1-10$.

[4] M. Merdzan, J. J. H. Paulides, and E. A. Lomonova, "Comparative analysis of rotor losses in high-speed permanent magnet machines with different winding configurations considering the influence of the inverter pwm," Ecological Vehicles and Renewable Energies (EVER), 2015 Tenth International Conference on, pp. 1-8, 2015.

[5] B. L. J. Gysen, K. J. Meessen, J. J. H. Paulides, and E. A. Lomonova, "General formulation of the electromagnetic field distribution in machines and devices using fourier analysis," Magnetics, IEEE Transactions on, vol. 46, no. 1, pp. 39-52, Jan 2010.

[6] D. G. Holmes and T. A. Lipo, Pulse Width Modulation for Power Converters, Principles and Practise. John Wiley and Sons, Inc., USA, 2003.

[7] Z. Q. Zhu, K. Ng, N. Schofield, and D. Howe, "Improved analytical modelling of rotor eddy current loss in brushless machines equipped with surface-mounted permanent magnets," Electric Power Applications, IEE Proceedings -, vol. 151, no. 6, pp. 641-650, Nov 2004.

[8] K. Yamazaki and A. Abe, "Loss investigation of interior permanentmagnet motors considering carrier harmonics and magnet eddy currents,' Industry Applications, IEEE Transactions on, vol. 45, no. 2, pp. 659665, March 2009

[9] C. Xiao, G. Chen, and W. Odendaal, "Overview of power loss measurement techniques in power electronics systems," Industry Applications, IEEE Transactions on, vol. 43, no. 3, pp. 657-664, May 2007.

[10] J. Pyrhonen, T. Jokinen, and V. Hrabcova, Design or Rotating Electrical Machines. John Wiley \& Sons, Ltd, 2008.

[11] S. R. Holm, H. Polinder, and J. A. Ferreira, "Analytical modeling of a permanent-magnet synchronous machine in a flywheel," Magnetics, IEEE Transactions on, vol. 43, no. 5, pp. 1955-1967, May 2007. 